\title{
Models of Hospital Acquired Infection
}

\author{
Pietro Coen \\ University College London Hospitals NHS Trust \\ United Kingdom
}

\section{Introduction}

This chapter will not dwell on how mathematical models are built, better covered elsewhere (Bailey, 1975; Renshaw, 1991; Scott \& Smith, 1994; Coen, 2007). It will focus on the impact of mathematical models on the understanding of infections spread in hospitals and their control. Hospital Acquired Infections (HAIs) made their first appearance with the invention of hospitals, mostly associated with surgical operations carried out when germ theory and hand-hygiene were unheard of and post-surgical mortality could be as high as $90 \%$ (La Force, 1987). The invention of antibiotics reduced mortality, but subsequently led to the emergence of infections adapted to survival in the antimicrobial-rich hospital environment. An arms race ensued where the bacterium and the pharmacist are to this day fighting to outwit each other (Sneader, 2005). Bacteria like Meticillin-resistant Staphylococcus aureus (MRSA) and Vancomycin-resistant Enterococci (VRE) were detected in UK hospitals as early as the 1960s (Stewart \& Holt, 1962), but it was not until the mid 1990s that they 'took off' as a significant problem for hospital managers and inpatients (Austin \& Anderson, 1999). If only $10 \%$ of adult HAI infections could be prevented, $£ 93$ million could be saved in England and Wales alone (Plowman et al., 1999).

Hospital inpatients are difficult subjects for study. They are only 'available' for a short time window, measured in days; too debilitated to all cooperate to the same degree; an extremely heterogeneous population; and major ethical issues are met when it comes to experimentation, especially when infection is asymptomatic. Their environment is heterogeneous and constantly changing, as technologies improve medical practice change. Under these circumstances, HAI models have a distinct advantage over uncontrolled observational studies (Cooper et al., 2003). This point is illustrated in section 4.2.

When designing the structure of a model it is necessary to strike a balance between realism and generality (Bonten et al., 2001). A model needs to be complex enough to capture all those essential features of the process under study, ensuring realism and providing sufficient information so that all questions can be addressed using the model framework. Yet models must not be too complex lest conclusions are only generalizable to a small number of situations of little interest for much of the health care public. As complexity increases, providing information for a model may become prohibitive, less tools for analysis may be available for checking errors in formulation, and exact solutions may not exist so that numerical approximations are needed. Nevertheless HAIs are complex things, and modellers are forced to abandon generality; at worst mathematical models may be too simple to be realistic. This chapter explores the nature of this complexity (Section 2), review 
methods used for fitting models to observational data (Section 3), focus on lessons learnt for some areas of infection control (Section 4). Finally I give an example of a stochastic model of norovirus on a geriatric ward (Section 5).

\section{Essential features of $\mathrm{HAl}$}

This in part depends on the questions addressed and the biological characteristics of the HAIs modelled. The general idea is that (susceptible) patients spend time on a ward, they have physical contacts with health-care workers ([HCWs] nurses, doctors, cleaners etc.), visitors, other patients and with contaminants in the environment. Such exposure can lead to colonization with infectious organisms that may sooner or later cause debilitating clinical infection. The devil is in the detail.

\subsection{Mechanism of infection}

Some HAIs manifest themselves soon after colonization, regardless of the kind of healthcare. This is typical of many viruses, such as varicella, measles, norovirus and adenovirus where susceptibles acquire infection and after an incubation period of a few days suffer symptoms of infection coincident with infectiousness to others and subsequently recover or die (section 5). Such aetiologies are typically associated with outbreaks characterized by 'attack rates' and outbreak durations.

In contrast most HAIs are not just about acquiring the organism. Many bacterial infections may be carried for months in the absence of clinical symptoms, such as in the nares (MRSA), the skin (Coagulase-negative Staphylococci [CNS]), the gastrointestinal tract (Escherichia coli, Clostridium difficile). This silent infection may last months to years, makes the patient a 'carrier', more or less infectious to others depending on the organism and other circumstances. Only when natural barriers are breached, often as a result of health-care intervention (e.g. surgery, line and catheter insertion), bacteria will invade tissues that are otherwise sterile, they multiply and cause life-threatening clinical illness. An extreme example is Streptococcus pyogenes (or Group A Streptococcus [GAS]), an airborne infection that typically causes sore throat, but can be life threatening if allowed to invade subcutaneous tissues (necrotizing fasciitis), such as via a stab wound or burn. Untreated it can result in multiple organ failure and very high fatality rates (Aziz \& Kotb, 2008).

Hence the epidemiology of most HAIs is the result of a two-step process: the acquisition of the organism (acting on susceptibles), and the subsequent invasion of sterile tissues (acting on carriers). The slow turn-over of carriage (relative to the average length of stay in hospital) means that these HAIs are typically endemic and their burden measured in terms of prevalence and incidence. The first step is usually modelled with the rate of infection per susceptible-carrier pair, known as the 'transmission coefficient', $\beta$ (Anderson \& May, 1991), sometimes factorized as $\beta=a b$, where $a$ is the contact rate and $b$ is the probability of transmission per contact (Austin et al., 1999a). The second step is modelled as a rate per carrier. For example, Coello et al., (1997) estimate $0.59 \%$ daily probability of MRSA carriers developing infection. Cooper and Lipsitch (2004) estimate 35\% per day for MRSA in ITU.

Other HAIs present with mixed aetiologies, such as $C$ difficile, which in one third of patients causes life threatening infection of the colon on acquisition, while two thirds remain asymptomatic. The latter may yet suffer infection as a result of as poorly understood 
triggers, such as antimicrobial administration (Johnson et al., 1990). Recent evidence suggests that norovirus is carried asymptomatically by $12 \%$ of individuals in the community (Phillips et al., 2010). Such carriers may well become infectious in hospital when diarrhoea sets in, perhaps the result of laxatives and antibiotics.

\subsection{Forms of clinical infection}

At one end of the clinical spectrum organisms enter the bloodstream through a cut in the skin, are able to multiply and systemically affect the rest of the body (bacteraemia or sepsis). Bacteraemias are relatively rare $(1.3 \%$ of all HAIs in England; Hospital Infection Society \& Infection Control Nurses Association, 2007), are expensive to treat and life threatening. Other infections are more localized in their effects. Surgical wounds may become infected (Surgical Site Infections [SSI]), causing a wide range of problems. Their seriousness depends on whether they are peripheral, deep incisional or whether inner body spaces and organs are affected (Health Protection Agency [HPA], 2011a). These are rarely life threatening, although they make up 16\% of all HAIs in England, are expensive to treat (Plowman, 1999), may lead to unpleasant consequences (delayed care) and if inappropriately treated may lead to bacteraemia, amputation and death. A milder form of HAI is the urinary tract infection (UTI) typically caused by insertion of temporary indwelling bladder catheters kept long enough for bacteria to move up the urinary tract and infect normally sterile sites such as the kidneys. UTIs are very common $(21 \%$ of all HAIs in England), and can lead to pain and distress, general debilitation and occasionally bacteraemia (Bryan et al., 1984).

Many mathematical models distinguish between carriers and clinical infections, but most lump all infections into one homogeneous black box, ignoring heterogeneity in frequency and consequences. Bacteraemias may be expensive to treat and life threatening, but contribute little to infectious spread. SSIs, on the other hand, are not as life-threatening, but are more common and more infectious. Treating SSIs and bacteraemias as a uniform entity may lead to significant discrepancy between model prediction and reality.

\subsection{The aetiological agent}

Most HAIs are caused by bacteria although viruses and fungi are often involved. Most are resistant to some classes of antibiotic. Examples from the Gram-positive bacteria are MRSA (penicillins and cephalosporins), VRE (some penicillins and glycopeptides), C difficile (fluoroquinolones). Many Gram-negative bacteria cause bacteraemias and UTIs, such as $E$ coli, Pseudomonas aeruginosa, Klebsiellas spp., Citrobacter, Enterobacter, and Proteus. Some of these produce enzymes known as extended-spectrum beta-lactamases (ESBL), which confer resistance to many antibiotic classes (penicillins, cephalosporins, fluoroquinolones and aminoglycosides) (Kullik et al., 2010). ESBLs are not a homogeneous group, inheritance may be chromosomal or via plasmid, and several genotypes exist (TEM-10, TEM-26, CTX-M etc.; Livermore 2001). Resistance to carbapenems, one of the last lines of defence against ESBLs, is beginning to emerge (Grundmann et al., 2011). Other bacteria are more sensitive to antibiotics but are common enough to cause significant infection (e.g. Meticillin-susceptible Staphylococcus aureus [MSSA]).

The genetic structure of most bacterial populations is clonal (Smith et al., 1993), and antibiotic-resistant HAIs are no exception, so that de novo emergence of antibiotic 
resistance is rare on the hospital-admission time-scale, and resistant variants may be modelled independently of sensitive counterparts. This is the case of MRSA and MSSA (Feil et al., 2003), E coli (Milkman \& Bridges, 1990), C difficile (Griffiths et al., 2010). In contrast, Enterococci (e.g. VRE) and Gram negatives like the Klebsiella exhibit considerable inter-strain genomic diversity, mainly linked to the presence of transposable agents such as phages and plasmids - often responsible for the resistance phenotype (van Schaik \& Willems, 2010; Zhao et al., 2010). It is then possible for sensitive variants to become resistant in hosts colonized with both variants.

Regardless of the genetics, there may be important differences between HAI genotypes. One example is $C$ difficile which has hundreds of different 'ribotypes'. Ribotype 027 can produce 16 to 23-fold higher concentrations of toxin (Warny et al., 2005) and is associated with twice the mortality than other strains (HPA, 2011b). Some $S$ aureus variants, known as community-acquired MRSA (CA-MRSA), produce the Panton-Valentine Leukocydin (PVL) toxin, are abundant in the community, are much more sensitive to antibiotics and are more associated with 'soft-skin' infections. But they are also known to cause life-threatening necrotizing pneumonia. CA-MRSA is on the increase in North America and is making its appearance in the hospital (David \& Daum, 2010), although relatively unknown in UK hospitals (HPA, 2011c).

Competition for colonization space is an interesting issue when modelling two or more variants. MRSA and MSSA, for example share the same ecologic 'niche' as they both colonize the nares of human beings, as well as many other aspects of infection aetiology and a degree of competition may well exist (Dall'Antonia et al., 2005). The problem is that most mathematical models of antibiotic resistance make implicit assumptions regarding competition with important implications on model dynamics (see section 4.3). These models either include two variants (sensitive and resistant), or only consider the resistant one. Onestrain models are consistent with complete coexistence with other variants (e.g. Austin et al., 1999a). Two-strain models are consistent with complete competition whenever the 'cocarrier' state is ignored (i.e. a resistant strain may not colonize a host that is already colonized with the sensitive strain; e.g. Austin et al. 1999b).

\subsection{The nature of infectious spread}

\subsubsection{Transmission routes}

Some modellers (Cooper et al., 1999, 2004a; Smith et al., 2004) followed the implicit approach of embedding all possible routes of infection within the value of the transmission coefficient $\beta$, which measures the effective transmission rate between any susceptible-infected pair, regardless of the exact route. Bootsma et al. (2007) estimate transmission coefficients for $3^{\text {rd }}$ generation cephalosporin-resistant Enterobacteriaceae (CRE) and consider the addition of the 'endogenous' route, whereby the patient's already present pathogens grow to detectable levels. They find this route to be responsible for more acquisitions than the cross-infection route, which brings into doubt the definition of 'hospital acquired' as infections detected 48 hours after admission for Enterobacteriaceae like $E$ coli.

Other modellers are more explicit and usually make the case for the predominance of a single transmission route. Examples are models of VRE and MRSA in ITU where patients are not free to move and transmission takes place via the HCW (Austin et al., 1999a; 
Grundmann et al., 2002). Failure of contact precautions is blamed for any transmission. If $P$ is the number of patients and $\mathrm{W}$ is the number of HCWs, the total number of infectious contacts per day is $\mathrm{C}=\mathrm{aPW}$ ( $a$ as defined in section 2.1). Notice that for a given total number of contacts $C$, the number of contacts per patient $(=a W)$ may not necessarily equal the number of contacts per $\mathrm{HCW}(=\mathrm{aP}=\mathrm{aP}(\mathrm{W} / \mathrm{P}))$. These are only expected to equal when the HCW-patient ratio is 1:1 (as maybe the case on the ITU). This is not realistic when some HCWs visit more patients than others.

In wards where patients are mobile, or where transmission can take the airborne route, more transmission coefficients are needed. The airborne route is especially relevant to the spread of pulmonary tuberculosis (TB), measles and influenza. Models of the airborne route require the measurement of parameters like quantum generation rates (a measure of infectious material in the air), room volume, room ventilation rates, pulmonary ventilation rates (Beggs et al., 2010). It is common practice to isolate patients susceptible to infection (e.g. immunocompromised cases) in isolation rooms with positive pressure (to keep infectious quanta out), and infectious cases with negative pressure (to keep infectious quanta within the confines of the isolation room). The implicit approach may still enable the analysis of the success of isolation, when different transmission coefficients are used, for isolated and non-isolated patients (Forrester et al., 2007).

\subsubsection{Quantifying transmission}

It is possible to follow a cohort of inpatients and measure the acquisition rate of infection (Jernigan et al., 1996). This is the 'force of infection', $\lambda$, and is equivalent to $\beta$.I, where I is the average number of infectious patients per unit time on the ward. It is possible to use this number to calculate $\beta$ from the expected number of daily visits to infectious patients. Raboud et al. (2005) estimate $\beta$ s for patient-HCW contact ranging from $0.017 \%$ to $6.7 \%$, depending on whether the patient was in isolation and whether HCWs complied with handwashing. Forrester et al. (2007) estimated $1.03 \%$ acquisitions per day (background rate, $\beta_{0}$ ) and transmission coefficients $\beta_{1}=1.31 \%$ (not isolated), and $\beta_{2}=0.45 \%$ (isolated). Cooper \& Lipsitch (2004) estimate transmission coefficients 33\% (MRSA), 26\% (VRE) for patients in ITU. Ong et al. (2008) used transmission coefficients for influenza stratified by 5 categories of staff, ambulant and non-ambulant inpatients and visitors.

Other modellers use the "basic case reproduction number", $\mathrm{R}_{0}$, as a summary measure of infectious spread (Anderson \& May, 1991). This is defined as "the average number of secondary infections produced when one infectious individual is introduced into [an infinite] host population in which every host is susceptible". It follows that the infection can persist in the population only when $R_{0}>1$. Real life populations are finite and seldom completely susceptible so that we are more likely to observe effective basic case reproduction numbers, $R_{e}=R_{0} . s^{*}$ where $R_{0}$ is discounted by the proportion of susceptibles in the population $\left(s^{*}\right)$. Cooper et al. introduced the refinement of having $R_{0}=R_{A} \cdot \xi$, where $R_{A}$ is the effective basic reproduction number observed within a single admission, and $\xi$ is a constant that accounts for the probability of re-admission while still infectious (Cooper et al., 2004a). The implication is that even when good infection control practice reduces $R_{A}$ to values less than 1, the infection will establish itself as a result of re-admission if $\xi$ is large enough. Cooper et al. chose transmission coefficients for MRSA consistent with $\mathrm{R}_{0}$ ranging between 1.1 (self-limiting clusters of secondary cases) to 1.3 (endemic pattern). 


\subsubsection{The role of the environment}

The hospital environment, as a source of infection, is an extremely complex entity and difficult to model explicitly. Hospital surfaces can harbour live HAI agents (e.g. Staphylococci, Enterobacteriaceae, $C$ difficile spores etc). The problem is that even where it is possible to establish associations between bacterial flora on patients and their immediate environment (Asoh et al., 2005), the direction of the causal arrow is not known. Wards are also extremely heterogeneous places. Bacterial counts sampled from sites most likely associated with direct patient contact (e.g. hand-rails, soap dispensers, bedding, curtains) are much lower than other sites (e.g. floor) (Hamilton et al., 2010), and porous surfaces are more difficult to clean (Oie et al., 2005). To explicitly model these environmental sites it is necessary to choose the appropriate site, sample for organisms at appropriate intervals, and follow up patients for contact rates with the site as well as their carriage status. An alternative is to model the environment as a black box and set its 'colonization' and 'turnover' rates, tweaking them so as to obtain a model output close to observation (Kouyos et al., 2011).

\subsection{The patient}

Many inpatients have co-morbidities that put them at special risk of infection: HIV cases, diabetics, bone-marrow transplant patients, those on chemotherapy, in elderly care wards, those undergoing surgery, to mention a few. There are behavioural differences: some patients are more likely to be re-hospitalized, and those with a history of hospitalization are more likely to carry HAIs. Cooper et al. (2004a) stratified patients into two categories of re-admission frequency (see section 2.7), while Bootsma et al. (2006) allowed 1\% of inpatients colonized with MRSA to be 'super-spreaders' (10 times more infectious than other carriers).

In the UK patients rarely stay on the same ward for the duration of their admission. There are at least two distinct patterns of patient flow (Figure 1): elective admissions, planned weeks or

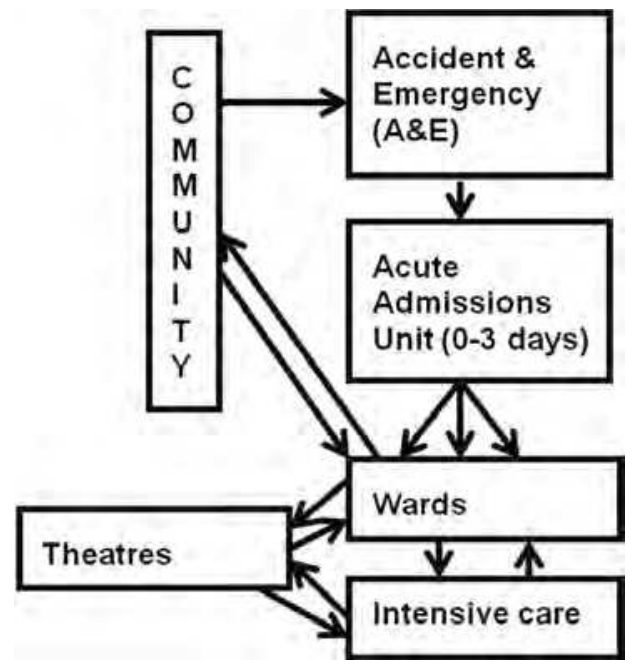

Fig. 1. Schematic description of patient flow in a UK hospital. 
months in advance, are usually taken directly to specialist wards. In contrast, emergency admissions present to A\&E and are subsequently moved to a temporary unit, known in the UK as the Acute Admissions Unit (AAU) and stay there for 1-3 days prior to being admitted to specialist wards. Patients may also be taken to ITU, infectious diseases wards, or may be moved to theatre to undergo surgery, to then recover in a different ward. The role of ITU is thought to be important in the seeding and spread of certain antimicrobial resistant HAIs to other wards (Edgeworth, 2011). Bootsma et al. (2006) and Hubben et al. (2011) modelled patients admitted to one of three hospitals with 36 wards each and 5 ITUs, whose inpatient population had differing lengths of ward stay depending on whether patients were in ITU (mean of 3 days) or other wards (7 days).

\subsection{The staff}

Some modellers assume all transmission between inpatients to take place via the medium of the ward environment - HCWs being part of it (Cooper et al., 2004a). Others explicitly model HCWs and are seen as the most responsible transmission component (Austin et al., 1999a). Because staff members work on on the ward for much longer than the average patient length of stay, they have a huge potential to spread infection. Hence they cannot play as large a role in transmission as inpatients lest we expect every inpatient to become infected (Beggs et al., 2008). HCWs are a heterogeneous group. Ong et al. (2008) stratified HCWs into cleaners, clerks, doctors, health-attendants, and nurses for an influenza model. Their "Who-Acquires-Infection-From-Whom" (WAIFW) matrix suggest heterogeneous contact rates with patients and each other: cleaners, health-care attendants and clerks mostly contacted nurses; doctors had them mostly with nurses, patients and their visitors; nurses had them mostly with other nurses, patients and visitors. Bootsma et al. (2006) stratified staff into those that have contact with patients on a single ward (1:1 staff patient ratios in ITU, and 5:18 ratios on other wards), and staff with unrestricted contact across wards and hospitals. Some have greater hand-hygiene compliance than others (Pittet et al., 1999). Raboud et al. (2005) stratified them into daytime and night-time staff and went as far as including the detail of staff looking after the patients of other staff during coffee breaks!

\subsection{The community}

Early HAI models ignored the impact of the population outside hospital walls (the "extramural" population), and patients admitted into hospital were either assumed uncolonized or came with a fixed probability of acquiring infection (Austin et al., 1999a; Lipsitch et al., 2000). Cooper et al. (2004a) broke this tradition and modelled the extramural population, stratifying it into those with a high vs. low rate of readmission $(0.57 \%$ vs. $0.06 \%$ readmissions per day). Hubben et al. (2011) stratify patients by ward within three hospitals and by risk of readmission with 22,000 'high-risk' patients who are 10 times more likely to be readmitted, out of a catchment population of 220,000 - resulting in $50 \%$ high risk patients within the hospital population. This kind of HAI model predicts low extramural MRSA prevalence, which matches observation (Lu et al., 2005). Austin \& Anderson (1999) modelled the spread of MRSA across 400 NHS hospitals in England and conclude that the largest hospitals are responsible for most 'transmission' events, and make the case in favour of active surveillance. 


\subsection{Infection control}

No hospital applies exactly the same infection control strategy as any another at any one time. Several interventions are invariably applied simultaneously. Many of the decisions taken by hospital managers are based on quasi-experimental and observational data at best. This point is illustrated in the review of the evidence in favour of inpatient isolation for the control of MRSA infection (Cooper et al., 2003; Cooper et al., 2004b). This is an area where mathematical models can contribute. As it is not possible to manipulate the real world of patients in hospitals, we can resort to manipulating a simulated hypothesis of it, and draw some conclusions, aware of all the assumptions made in its design. One approach is to fit the model to infection data and estimate unknown parameters (see section 3), and subsequently to use it to run simulations and test infection control strategies (Section 4).

Some infection control methods are easier to model because they directly affect the transmission cycle: cohorting (Austin et al., 1999a), hand-hygiene (Austin et al., 1999a; Beggs et al., 2008, 2009), isolation (Cooper et al., 1999, 2003). Cohorting, the neutralization of transmission routes into 1:1 HCW:patient contacts, is only possible in settings where staff numbers exceed patient numbers, such as on the ITU. On other wards patients can exceed staff numbers by at least 5:1, and only degrees of cohorting are possible, especially when patients are mobile (see section 5; Raboud et al., 2005). Hand-hygiene, the cleaning of staff hands before and after patient contact, has two dimensions (Beggs et al., 2008): compliance (the proportion of staff that actually clean their hands) and effectiveness (the probability of effective removal of contaminants during hand-cleaning). The problem with most handhygiene models is their assumption of a linear relationship between hand-washing compliance and the reduction of the transmission coefficient, $\beta$ - for which there is no evidence. If effectiveness is inversely proportional to compliance non linear effects are expected (Coen, 2007). Isolation, the removal of patients into secluded areas so as to prevent contacts with other patients, does not eliminate transmission completely (Forrester et al., 2007; Cepeda et al., 2005), and moving patients to isolation facilities comes with a risk of death on the ITU (section 4.2). Modelling isolation is achieved by adding isolated 'categories' of patients in the model structure (e.g. Cooper et al., 1999). More difficult is to include the realism of true isolation which is the result of competition with a range of other priorities, such as privacy, dignity, avoiding disturbance from difficult patients, and infections caused by other organisms (Jeanes et al., 2011).

Other interventions are the control of hospital demography (closing wards to admissions; sending affected staff home; Section 5), environmental cleaning whose effectiveness is difficult to measure; surveillance and feedback, such as the health-care bundle audits and screening of patients on admission (Raboud et al., 2005; Hubben et al., 2011; section 4.1); antibiotic usage (section 4.3). The practice of training staff to minimize infection risk, such as in the safe taking of blood, the insertion of central lines and catheters, has never been modelled and requires the colonization vs. infection stratification (section 2.1). Rare are the models where several infection control method are compared simultaneously (Austin et al., 1999a; Raboud et al., 2005; Hubben et al., 2011).

\subsection{Small population sizes and the role of chance}

Even the largest hospitals are broken up into wards which are small enough to make chance events of significant importance. Observing zero cases in a particular month does not mean 
absence of transmission, and in doing surveillance it is necessary to gather infection data over a wide time period in order to obtain a reliable average incidence rate. For this reason stochastic models (which approximate the probability distribution of model behaviour) are preferable to deterministic models (which approximate average model behaviour). The advantage of stochastic models - also known as Markov Chain Monte Carlo (MCMC) models - is that they give an indication of the variability in the expected trends (Renshaw, 1991). This variability can be so significant that control measures expected to be successful on average can fail "catastrophically" as a result of chance alone (Cooper et al., 2004a). Their disadvantage is that when parameters are unknown, computer-intensive statistical methods are needed to obtain estimates (section 3). There are many examples of HAI stochastic models: MRSA (Cooper et al., 2004a; Raboud et al., 2005; Hubben et al., 2011), VRE (Austin et al., 1999a), influenza (Ong et al., 2008), Severe Acute Respiratory Syndrome ([SARS]; Fukutome et al., 2007) and norovirus (section 5).

\subsection{The finance}

Treating infections costs money, so that spending money to implement infection control can save money. Hence, it is important to show that infection control interventions are cost effective. Mathematical models can help provide estimates of the number of cases prevented, N, as a result of intervention. This was done for MRSA screening (Raboud et al., 2005; Hubben et al., 2011). If $C_{T}$ is the cost of treating one infection, $C_{I}$ the overall cost of intervention then the cost per case averted (or the 'average Cost Effectiveness Ratio' [aCER]), is $\mathrm{C}_{\mathrm{I}} / \mathrm{N}$. The net benefit of an intervention is given by $\left(\mathrm{N} \times \mathrm{C}_{\mathrm{T}}\right)-\mathrm{C}_{\mathrm{I}}$. The aCER is an indication of the return to the health-care system for each $£$ spent. A positive net benefit indicates that the intervention will save money. It follows that it does not pay to prevent a rare infection (low $\mathrm{N}$ ) unless treatment costs are sufficiently high (large $\mathrm{C}_{\mathrm{T}}$ ), and intervention costs, $C_{I}$, are low. Estimates of $C_{T}$ for MRSA infections are $\$ 10,000-\$ 16,000$ (Raboud et al., 2005). In the mid 1990s Plowman et al. (1999) estimated $\mathrm{C}_{\mathrm{T}}$ of $£ 5397$ (bloodstream infections), $£ 2398$ (lower respiratory tract infections), $£ 1618$ (SSIs), £1237 (UTIs) and $£ 9152$ (multiple infections). Lopman et al. (2004) estimate costs per norovirus inpatient bed-day of $£ 145$ (elderly care ward).

\section{Dealing with unknown parameters}

The design of a mathematical model should be informed by observation. There are numerous ways to achieve this. Some parameters can be 'fixed' by using estimates from direct measurement possibly from the literature (e.g. the mean duration of infection). WAIFW matrices were estimated from conversations (surrogates of infectious contacts) for varicella (Zagheni et al., 2008), and from direct observations of HCW and patients the wards (Ong et al., 2008). Overlapping stay on the same ward (available from hospital computer records) can be used as surrogate measures of exposure to HAI cases. Alternatively sensitivity analysis uses a range of plausible values and the outcomes compared. Examples are screening costs (Hubben et al., 2011), contact rates (Beggs et al., 2008), days from detection of the index case to isolation of SARS cases (Fukutome et al., 2007).

Another approach is to identify the range of parameter values that minimize the discrepancy between model and data. This is usually done via numerical minimization 
algorithms such as Powell's direction set methods (Press et al., 1994; Chapter 10). Maximum likelihood uses the probability of observing some body of data, $\mathbf{y}$, when the model $\boldsymbol{\theta}$ is 'true', and is usually presented as $l=p(\mathbf{y} \mid \boldsymbol{\theta})$, where $\mathbf{y}$ are the data and $\boldsymbol{\theta}$ the unknown model parameters (Edwards, 1972). Confidence intervals may be achieved by means of profile likelihood methods (Aitkin, 1998; Press et al., 1994; Chapter 15). This was applied to timeseries data of the inpatient 'admission experience' (dates of admission and discharge, swab test dates and results, dates of isolation). The unknown part of the model was kept to a minimum (e.g. transmission coefficients and dates of acquisition of carriage) (Pelupessy et al., 2002; Cooper \& Lipsitch, 2004; Bootsma et al., 2007). Cooper and Lipsitch (2004) applied a hidden MCMC model to time-series of MRSA, VRE and resistant Gram-negative rods (RGNR) clinical infection in order to estimate parameters such as the patient-patient transmission coefficient $(\beta)$ and the probability of colonization on admission (v). A 'hidden' MCMC model (based on $\beta$ and $v$ ) described colonization and a Poisson process of rate $\lambda$ described infection rates per carrier. Their model gave superior fits to HAI data compared with quality control processes based on the Poisson distribution (Grigg et al., 2003). The latter are nevertheless useful to the local ward manager as null models, the lack of fit indicating the existence of infectious spread (and infection control breakdown), than the estimate of transmission parameters whose confidence intervals may be wide.

Bayesian methods have been applied to iterative MCMC models (Forrester et al., 2007; Kypraios et al., 2010). These are based on sampling algorithms known as the Gibbs' sampler and Hastings-Metropolis, which are based on Bayes' Theorem (Carlin \& Louis, 2000). This states that the probability of the model is proportional to the likelihood multiplied by the 'prior' probability of the model, $\Pi(\theta)$, or

$$
p(\theta \mid y)=p(y \mid \theta) \cdot \pi(\theta) \cdot \frac{1}{D}
$$

where $\mathrm{D}$ is the marginal probability of the data, across all possible models: $\mathrm{D}=$ $\int p(y \mid \theta) \Pi(\theta) d \theta$. The probability density function $p(\theta \mid y)$ is the 'posterior' density of the unknowns. It is the weighted average of the 'prior' probability and the weights are the likelihoods. When prior knowledge is unavailable, $\Pi(\theta)$ is set equal for the entire parameter space $\boldsymbol{\theta}$ (a 'non-informative' prior).

When $\mathrm{D}$ is known the posterior probability density is said to be available in 'closed form' and the Gibbs sampler makes use of standard density functions (e.g. Gamma, Beta etc.) where the same algebraic form exists for the prior, the likelihood and the posterior. An example is the Beta distribution for proportion data $y / n$, used by Forrester et al. (2007) to estimate MRSA test sensitivity. The Gamma distribution is used for count data, the Inverse Gamma for variances (Carlin \& Louis, 2000).

For more complex models D may be impossible to compute, and the Hastings-Metropolis approach can be used instead (Metropolis et al., 1953). A likelihood function is considered for each unknown parameter in turn, conditional on the data and the other unknown parameters. This is equivalent to the full likelihood with all other unknown parameters fixed, e.g. $\mathrm{p}\left(\mathrm{y}, \theta_{1} \mid \theta_{2}, \theta_{3}\right)$. The algorithm works by iteratively sampling a 'candidate' parameter value, say $\theta_{1}{ }^{*}$, from a 'proposal distribution' which may be the prior density function, $\Pi(\theta)$, or a multivariate normal density with means $\mu=\left(\theta_{1}, \theta_{2}, \theta_{3}\right)$ and some 
variance-covariance matrix $\Sigma$ (Carlin \& Louis, 2000). The candidate density is then accepted with probability $r$ where

$$
r=\min \left[\frac{p\left(y, \theta_{1}^{*} \mid \theta_{2}, \theta_{3}\right) \cdot p\left(\theta^{*}\right)}{p\left(y, \theta_{1} \mid \theta_{2}, \theta_{3}\right) \cdot p(\theta)}, 1\right]
$$

The list of accepted parameter values makes up the Markov chain. No matter what starting values for $\boldsymbol{\theta}$, the chain converges to the posterior distribution. When discarding the first 500 iterates or so we obtain an 'ergodic' chain whose distribution can be used to measure confidence intervals for the estimates.

Forrester et al. (2007) applied a mixture of MCMC approaches to MRSA carriage data from a patient cohort admitted to a 12-bed ITU with 2 isolation rooms. Their parameter space, $\boldsymbol{\theta}=$ $\left(\beta_{0}, \beta_{1}, \beta_{2}, \varphi, \rho\right)$ is represented by a background infection rate $\left(\beta_{0}\right)$ and transmission coefficients $\beta_{1}$ (from other patients) and $\beta_{2}$ (from patients in isolation rooms), as well as the probability of colonization on admission to the ITU $(\varphi)$ the sensitivity of the MRSA screening test $(\rho)$, the time of MRSA colonization, $c_{i}$, for patient $i$. The data were dates of admission $\left(\mathrm{a}_{\mathrm{i}}\right)$, first positive swab $\left(\mathrm{v}_{\mathrm{i}}\right)$, isolation $\left(\mathrm{q}_{\mathrm{i}}\right)$ and discharge $\left(\mathrm{r}_{\mathrm{i}}\right)$. For a discussion of results see Section 4. Similar approaches have been used for Stapylococcus aureus (McBryde et al., 2007), VRE (Cooper et al., 2008) and swine flu (Hohle et al., 2005).

There is a philosophical problem with more realistic (and complex) models. The model may never fit the precise circumstances of the data, and estimated parameters may not be truly representative of the target situation. This is the case of norovirus outbreaks (section 5), with rare epidemics involving small numbers of cases, each on different wards with their own idiosyncratic sets of infection control approaches and patient management. Even when epidemic data are available for such a specific settings it is by no means certain that they are representative of a common 'true' underlying model. A pragmatic approach is to illustrate a point by using a set of parameter values vaguely consistent with observation.

\section{Some conclusions from the literature}

\subsection{Screening and surveillance}

The advantage of screening is three-fold: 1) detection protects the positive case when measures are taken to clear carriage; 2 ) isolation of positives prevents transmission to other inpatients; 3) removal of carriage from the community means less imported cases in future re-admissions. Bootsma et al. (2006) used a stochastic model to compare six infection control components that are part of what is known as the "search and destroy" approach, including the passive treatment and isolation of known MRSA carriers, the screening of all patients and health-care staff in affected wards, and the eradication of colonization at discharge. They find that treatment of known carriers and screening of contact patients can bring down prevalence from $15 \%$ and maintain low endemicity $(<1 \%)$, but additional screening (such as of staff in affected wards) does not offer additional benefit.

The paradox is that when HAI screening is successful it becomes less cost effective (Raboud et al., 2005; Hubben et al., 2011). Raboud et al. modelled a Canadian hospital ward with $1.3 \%$ MRSA prevalence and showed that culture-based MRSA screening is cost-effective so long 
as there is at least 1 case for every 2 to 3 years, but MRSA infection is too infrequent to justify a more expensive molecular test. Hubben et al. compared two settings: high prevalence $(15 \%)$ vs. medium prevalence $(5 \%)$ of MRSA carriage. The molecular test was more cost effective at high prevalence, whereas the culture based chromatogenic test was more cost effective at medium prevalence, in spite of the advantages of molecular tests (high sensitivity, result in hours).

Robotham et al. (2007) use a stochastic model and find random screening (at rate $\varphi$ per patient per day) more effective at detecting MRSA carriers than screening a proportion $\omega$ of all admissions. While this is a more realistic model as it assumes limited isolation capacity (20 rooms), the bizarre result is more likely the result of the unrealistic assumption of a homogeneous inpatient population and randomly distributed MRSA carriers within it. Their baseline $40 \%$ prevalence is an extreme exaggeration ( 5 to $10 \%$ would be more likely) and the assumption of no infection control other than isolation is unrealistic. Ultimately admission screening is reputed successful, partly because it targets prevalence in the fraction of the catchment population re-admission risk and partly because it targets patients in ITU, an important reservoir "for generating and then seeding the rest of the hospital with MRSAcolonized patients" (Edgeworth, 2011).

\subsection{Isolation}

The practice of isolation originates at least from the 1600s, when those affected by the plague were isolated in secluded buildings (Cipolla, 1973). The evidence in favour of isolation on the hospital ward may depend on the type of ward. Cooper et al. $(2003,2004 \mathrm{~b})$ carried out a Cochrane review and identified 46 studies that addressed the issue. Not one study was fully clear of methodological shortcomings. The authors subsequently designed and carried out a new study to address such study design problems (Cepeda et al., 2005). They chose ITU inpatients, a study population with special issues around the act of switching off life support machinery in order to move patients to isolation facilities and measured acquisition of MRSA carriage and infection over a period of 12 months as outcome. They applied a quasi-experimental cross-over design comparing isolation with no isolation, and controlled for numerous potential confounders such as nursing hours per patient, severity of underlying disease and antibiotic usage. No beneficial effect of isolation was detected (multivariate relative risk of infection for non-isolation: $0.73,95 \%$ confidence intervals: 0.49 1.10). Unfortunately their design lacked adequate temporal controls leaving conclusions open to uncertainty. Hand-hygiene compliance in staff was also low $(21 \%)$ and isolation was not expected to work anyway (Huskins \& Goldmann, 2005).

By contrast, Cooper et al. (2004a) used a stochastic model of MRSA in a homogeneous 1000 bed-hospital and showed that 20-bed isolation units are successful in controlling and eradicating MRSA from hospital inpatients, so long as $R_{0}<1.3$, although this can take as much as 15 years to achieve. This is consistent with "search and destroy" being effective only in low-prevalence situations such as in Denmark and the Netherlands (Wertheim et al., 2004). In high endemic countries (e.g. USA and UK), isolation alone is not sufficient, especially if isolation is not $100 \%$ efficient. Forrester et al. (2007), estimate non-zero transmission rates from isolated inpatients $\left(\beta_{2}=0.0045\right)$, although smaller than for nonisolated patients $\left(\beta_{1}=0.0131\right)$. 


\subsection{Antimicrobial resistance}

Early models of antibiotic resistance were deterministic and concerned large host populations (Levin, 2002). Austin et al. (1999b) modelled bacterial carriage, where individuals may be colonized with one of two possible variants (one susceptible and one resistant to antibiotics) and may or not be treated with antibiotics. The absence of a cocarrier state means the two variants compete for colonization space. In the absence of antibiotics the sensitive variant has a selective advantage (greater transmission coefficient). They fitted the model to $\beta$-lactam resistance in Moraxella catarrhalis from Finland (where cephalosporin usage increased), and to penicillin-resistance in pneumococci from Iceland (where antibiotic usage declined) and found that significant reductions in resistance require equally significant reductions in drug consumption.

Lipsitch et al. (2000) used a similar deterministic model for antibiotic resistance in the hospital, with the addition of categories of 'history of past usage'. They found that when reductions in antibiotic usage are implemented, the response is rapid-weeks to monthsthe dynamics being driven by replacement of resistant variants by sensitive admissions. Unfortunately this prediction is not always consistent with observation (Enne et al., 2001; Sundqvist et al., 2010; Cook et al., 2004), possibly due to compensatory mutations that counter genetic costs of resistance (Wijngaarden et al., 2004; Besier et al., 2005) or because resistance to one antibiotic is genetically linked to resistance to other antibiotics that are still in use (Enne et al., 2004; Fraser et al., 2005). The expectation of a 'rapid' response may also be explained by the implicit assumption of $100 \%$ competition for 'susceptible space' between variants. The inclusion of a co-carrier state in the model would allow for milder forms of competition, and slower responses to changes in antibiotic usage.

Similar work focused on optimal empirical treatment strategy, when sensitivity knowledge is absent or delayed. Haber et al. (2010) used a stochastic, model and concluded that antimicrobial resistance should drop within months (rather than years) when a switch to second-line drugs is made. Kouyos et al. (2011) modelled MRSA carriers and infections on a 20-bed ward assuming clinicians can choose between two broad spectrum antibiotics (A and B) while they wait for antibiotic sensitivity results from the laboratory (so that a narrowspectrum drug can be given). They compared the performance of a number of empirical treatment strategies: mixing (simultaneous use of different drugs in different patients), cycling (sequential use of different drugs), and informed switching strategies (ISS) which can take many forms. Sensitivity analyses showed the optimal strategy to be ISS with deployment of drugs at frequencies inversely proportional to their respective resistance frequencies, especially if historical data are used (their $\mathrm{ISS}_{7}$ ).

\subsection{Barrier precautions and cohorting}

Sebillé et al. (1997) used a deterministic model of $S$ aureus, and showed that it takes $>60 \%$ hand hygiene compliance to reduce prevalence from 30\% to below $20 \%$. Austin et al. (1999a) used a deterministic model of VRE where patients and staff infect each other by direct contact. They find the role of barrier precautions (gowns, gloves and hand-hygiene) and cohorting of major importance in controlling VRE infection. This is probably because they ignore the effect of environmental contamination on transmission, a choice based on pulse field gel electrophoresis of bacteria isolated from patients, HCWs and the environment 
(Bonten et al., 1996). Raboud et al. (2005) used a similar model and made compliance dependent on the type of contact: with non-isolated patients (low-risk visits, $34 \%$ vs. highrisk visits, $74 \%$ ), and isolated patients (low-risk visits, $75 \%$ vs. high-risk visits, $85 \%$ ). They show that increasing hand-hygiene compliance by just $10 \%$ can result in a $50 \%$ reduction in the number of MRSA cases. Grundmann et al. (2002) applied the same model of Austin et al. to MRSA, and conclude that a $10 \%$ increase in hand-hygiene compliance might compensate the ill effects of staff shortage, though very difficult to achieve because above a certain level of compliance hand-hygiene gets in the way of life-saving action.

Beggs et al. (2008) use a modified version of an earlier model used by Cooper et al. (1999) where the patient-staff contact structure is explicitly modelled (as in Austin et al. 1999a), except that they distinguish between hand-hygiene compliance from hand-hygiene efficacy. They argue that a low hand-hygiene rate (20-40\%) is enough to control $S$ aureus infections, and additional improvements in compliance yield diminishing returns. Their deterministic model is however not ideal for a population of 20 inpatients and 3 staff members. The assumption of equal patient-staff and staff-patient contact rates is unrealistic (Ong et al., 2008). Beggs et al. (2009) reach similar conclusions with a stochastic approach. In each simulation the HCW makes 100 journeys from patient A (the source of MRSA) to patient B. MRSA is transmitted from A to HCW (with probability $\mathrm{p}^{\prime}$ ) and from $\mathrm{HCW}$ to patient $\mathrm{B}$ (with probability $\mathrm{p}$ ). The integer of a normally distributed random number gives the number of hand hygiene events out of 100 journeys. Each batch of journeys is repeated 1000 times. Should transmission occur between A and B, the risk of infection is 1 if no hand hygiene event takes place, and $1-\lambda$ otherwise $(\lambda$ is hand-hygiene efficacy). They use $\mathrm{p}^{\prime}=0.4$ and $\mathrm{p}=0.1$ as estimated for VRE in the intensive care unit (Austin et al., 1999a), an odd choice given that it is meant for MRSA (supposedly 0.15 and 0.01 respectively; Grundmann et al., 2002). The hand-hygiene efficacy was either $\lambda=0.58$ (antibacterial soap) or $\lambda=0.83$ (alcohol-based solution). No indication is given as to how the standard deviations were chosen. They suggest that when hand hygiene compliance is low the alcohol-based solution confers little advantage. Their model seems unrealistic as infection is only allowed in one direction, there are only 4 patients at most, and the HCW is not allowed to infect multiple patients.

\section{Norovirus on a UCLH elderly care ward}

In January 2009 a 63-bed ward in a UCLH hospital had an outbreak of norovirus affecting 39 cases (only 19 of which were laboratory confirmed). The time-line of the outbreak is shown in Figure 2.

\subsection{The model}

In collaboration with the HPA work began to gather data to inform a MCMC model of norovirus spread among inpatients and staff on a ward stratified into bays. The idea was to build an outbreak simulator flexible enough to help members of the infection control office make decisions during an outbreak. On a day-to-day basis, they would alter the settings so as to match the ward 'state', as well as specifying the infection control strategy of interest. Figure 3 illustrates in more detail the spatial structure of the ward affected by the outbreak: 13 bays ( $3-4$ beds each), and 7 isolation rooms. Users could then run batches of simulations and learn from the outcome. 


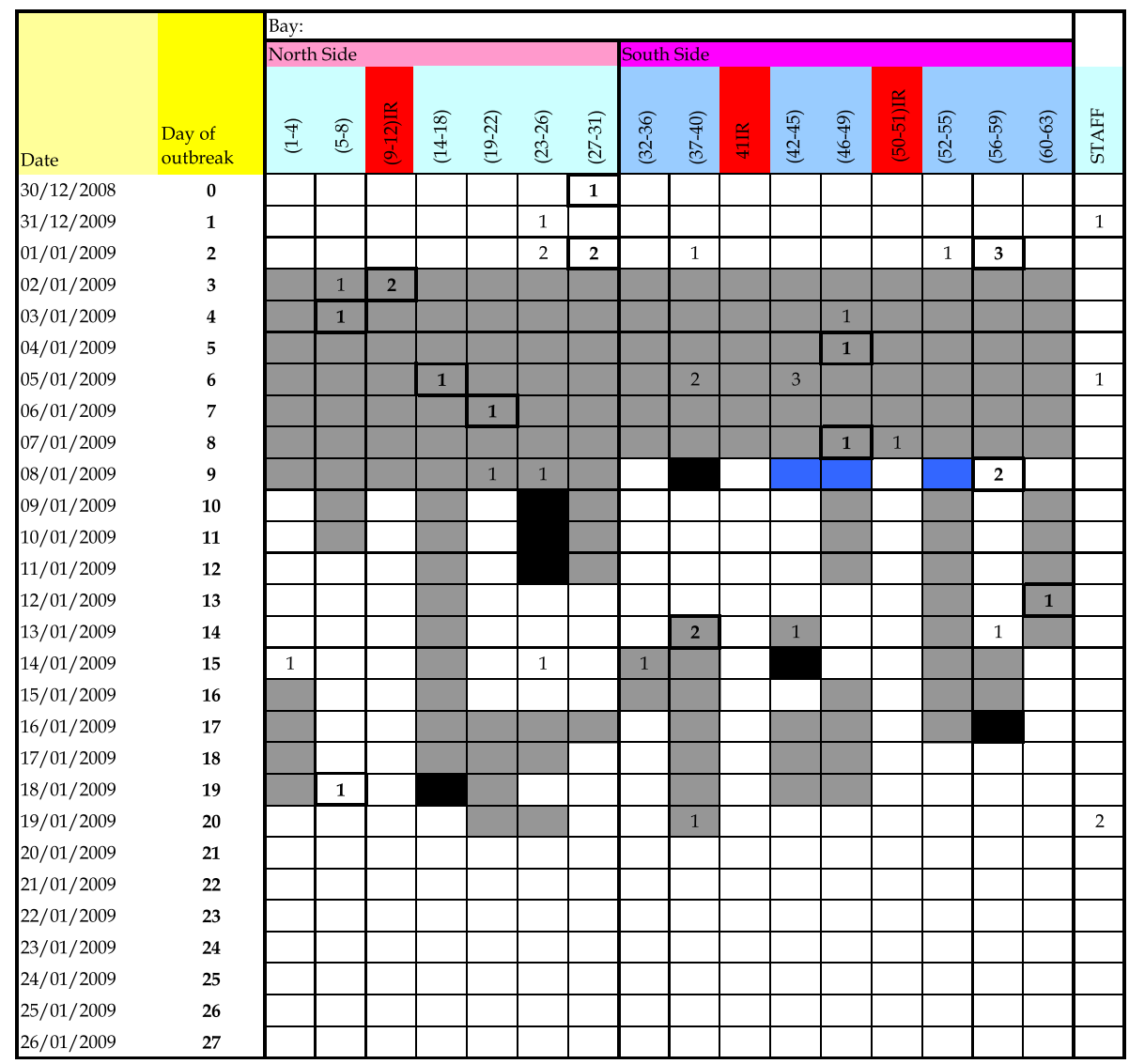

Fig. 2. Time-line of UCLH outbreak. IR = isolation room, each column represents one bay (beds numbered in brackets); numbers are cases (laboratory confirmed if in a bold square). Bays were closed to admission (grey squares), turned into isolation wards (blue squares) and deep cleaned (black squares).

The model concerns the infectious status of individuals (inpatients and staff) and inpatients are mapped on beds nested within bays. Patient and HCW movements are implicitly modelled via transmission coefficients stratified so as to distinguish between contacts within a bay $\left(\beta_{0}\right)$, across bays $\left(\beta_{1}\right)$ and with HCWs $\left(\beta_{2}\right)$. Transmission from isolation rooms is assumed nil. The $\beta_{\mathrm{s}}$ were chosen so as to match the known distribution of outbreak sizes, and attack rates in inpatients and staff from UK hospitals (Lopman et al., 2004; Harris et al., 2010), matching interquartile ranges for outbreak sizes (6 to 92 days) and attack rates (6\% to $65 \%$ for inpatients and $18 \%$ to $43 \%$ for staff). Each Member of staff is assigned a selection of bays. Bed occupancy may be under $100 \%$ and discharged patients are immediately replaced with a new admission (not necessarily to the same bed as the dischargee). Cases may not be discharged until they have recovered. Staff members 'rotate' shifts of 5 working days each and 2 days leave in between. Diarrhoea caused by agents other than norovirus (e.g. antibiotics, other viruses) affects $5 \%$ of inpatients. 


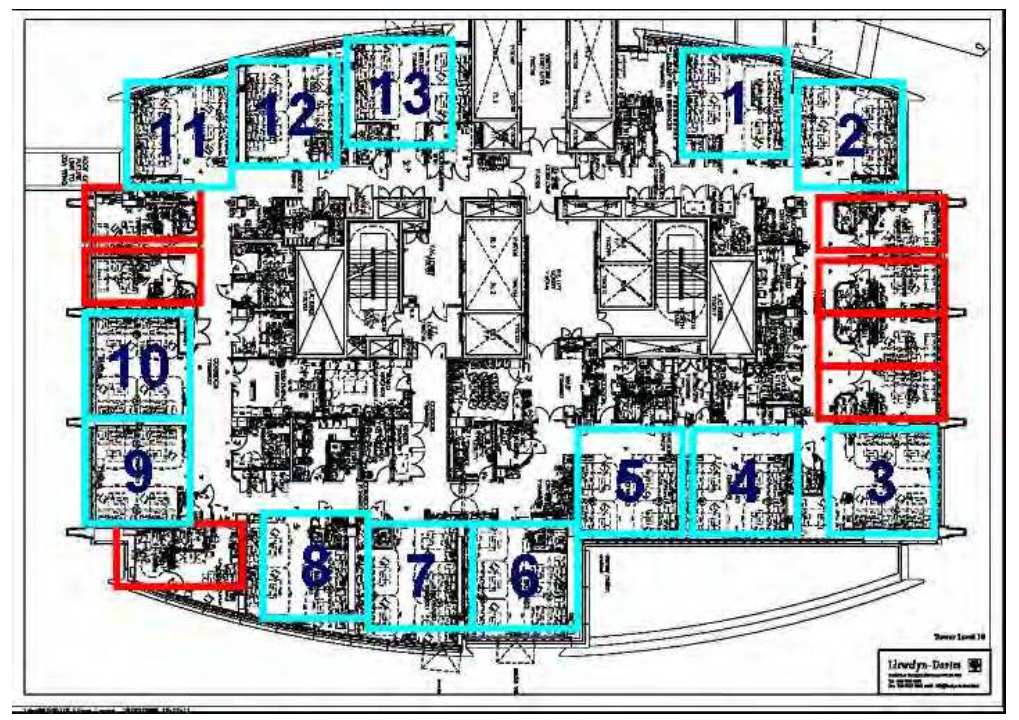

Fig. 3. Layout of the UCLH geriatric ward affected by the norovirus outbreak (blue squares indicate bays, and red rectangles are isolation rooms).

A 60 day simulation period is split into 'time steps' of width $\Delta \mathrm{t}$ (starting with $\Delta \mathrm{t}=3$ hours). For some events (acquisition of norovirus, detection of norovirus in the laboratory, acquisition and recovery of norovirus-unrelated diarrhoea) we used exponentially distributed waiting-time probability methods, equivalent to Poisson distributed numbers of events per time step (Ross, 2006). When the probability of two or more events per time step exceeded 0.01 , we halved $\Delta t$. For other events, we sampled from exact distributions. Times to discharge are sampled from the observed distribution of length of stay on this ward for January 2008 (mean 7.2 days), in the absence of an outbreak. Times to onset of symptoms come from experimental studies on US convicts (mean 36 hours, Wyatt et al., 1974) and times to recovery come from observational work from the Avon region, UK (Lopman et al., 2004). Immunity to norovirus was initially set to $30 \%$ in patients and $60 \%$ in staff members.

Each simulation begins with the introduction of an infectious individual admitted to a random bed. Not all seeding events result in an outbreak. Most outcome measures (attack rates, outbreak durations, bed days lost to closing bays or wards to new admissions) are obtained from the subset of 200 simulations where an outbreak did take place. On acquisition individuals incubate norovirus, then become infectious and finally recover into the immune category. Two definitions of a norovirus 'case' were investigated: a) laboratory confirmed positives with 50\% sensitivity (Vinjé et al., 2003; de Bruin et al., 2006) and a 1 day average delay to laboratory result, or b) acquisition symptoms (diarrhoea and/or vomiting).

Infection control measures take place 3 days after an outbreak is declared (two cases within seven days of each other) and include i) isolation of 'cases' into one of the isolation rooms, depending on availability (initially assumed fully occupied); ii) closure of affected bays to admissions until the last bay patient has recovered; iii) closure of the whole ward to readmission until the last case of the outbreak has recovered; iv) affected staff are sent home and may not return to work until 48 hours after recovery; v) restriction of patient-staff 
assortment (baseline: 6 staff members look after beds 1-31, the other 6 look after beds 32-63, as observed on the UCLH ward).

\subsection{Results and discussion}

The outcomes of three control strategies are shown in Fig. 4. In comparing strategies, medians are not as meaningful as ranges. Waiting for laboratory confirmation is equivalent to no control, because of the delay to the laboratory results, and low test sensitivity (half the cases missed). Acting on symptoms works best, except that in wards with non-specific symptoms it leads to unnecessary bay closures (Fig. $4 \mathrm{~b}$ ). Closing the ward leads to short term losses in patient-days, but control is swift and the outbreak is soon over, with little variability in outbreak sizes. These strategies are extremes and serve only for illustration. In real life managers are more likely to adopt mixed strategies: closing the ward for a few days using laboratory confirmation, and as cases become rare switching to closing only affected

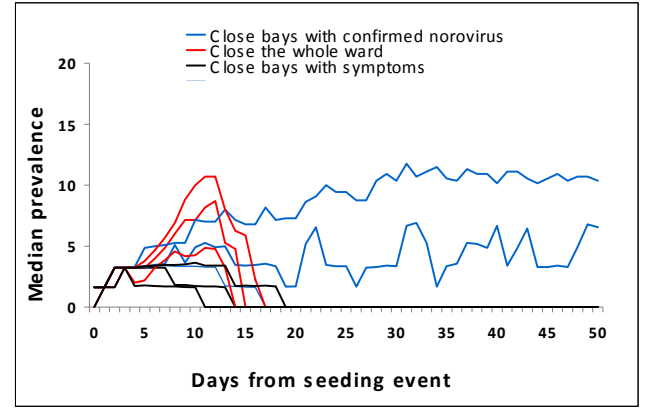

a) Norovirus prevalence (\%)

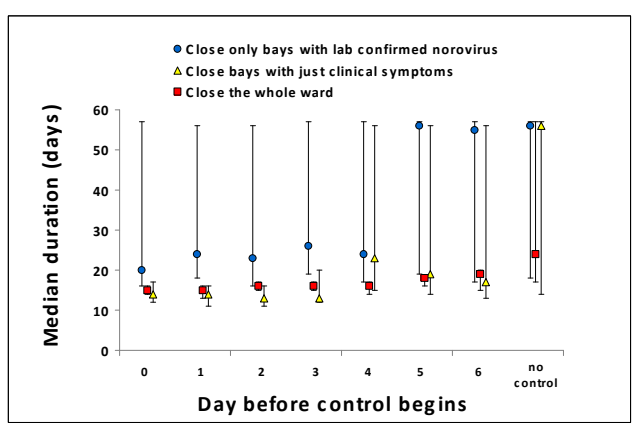

c) Outbreak duration (days)

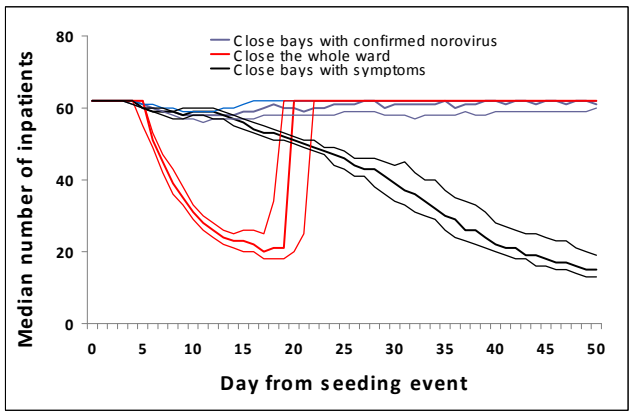

b) Number of inpatients

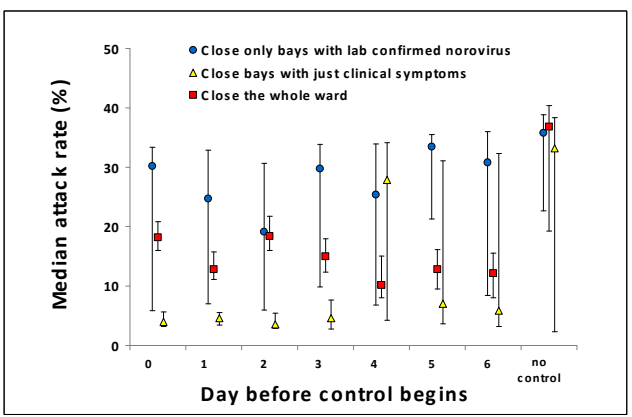

d) Attack rates (\% patients)

Fig. 4. Output of the stochastic model. Lines and error bars represent the median, $10^{\text {th }}$ and $90^{\text {th }}$ centiles.

bays (Fig. 2). The model could be made more realistic, allowing for mixed strategies. Transmission could be made dependent on actual distance between bays. This may not be necessary when patients do not move (e.g. ITU) and when they move 'too much' (physical distance being no distance). Environmental contamination could be added, allowing 
investigation of the impact of deep cleaning. Another aspect is building design. In our case we had an open ward where patients could infect other patients $\left(\beta_{0}>\beta_{1}>0\right)$. Some wards have physical barriers (rooms rather than bays), and HCWs become the main transmission vectors, allowing barrier precautions as well as relative cohorting to be much more effective.

\section{Conclusions}

The ideal HAI model is stochastic, simulates patient movement between wards of a set of hospitals, stratifies model parameters according to ward location (ITU, AAU, surgical, geriatric, infectious diseases wards etc.), stratifies the extramural population by readmission rate, stratifies by different categories of HCW, accounts for surveillance and delays in diagnosis, includes antibiotic usage, contaminated environment, and allows for all possible forms of infection control. In reality this level of complexity is not necessary to address questions for a specific setting. Most HAI models deal with MRSA in ITU, a mere fraction of all HAIs. The main lesson is there is no universal answer. Success depends on local conditions (e.g. epidemic/endemic setting, patient mobility, aetiological agent, treatment and intervention costs).

\section{Acknowledgments}

Thanks to Annette Jeanes and the UCLH Infection Control team for their insights into the management of hospital outbreaks, to Ben Lopman for his support in model development, to David Ramlakhan for introducing me to the Perl programming language, assisting me in the implementation of its functionalities, the provision and management of SQL databases and for storing and accessing infection records.

\section{References}

Aitkin, M. (1998). Profile likelihood, In: Encyclopedia of Biostatistics, Armitage, P. \& Colton, T., pp. 3534-3536, John Wiley \& Sons, ISBN 0-471-97576-1, Chichester, United Kingdom

Anderson, R.M. \& May, R.M. (1991). Infectious Diseases of Humans, Dynamics and Control, Oxford Science Publications, ISBN 0-19-854599-1, Oxford

Asoh, N.; Masaki, H.; Watanabe, H.; Watanabe, K.; Mitsusima, H.; Matsumoto, K.; Oishi, K. \& Nagatake, T. (2005). Molecular characterization of the transmission between the colonization of methicillin-resistant Staphylococcus aureus to human and environmental contamination in geriatric long-term care wards. Internal Medicine, Vol. 44, No. 1, (January 2005), 41-5, ISSN 0918-2918

Austin, D.J. \& Anderson, R.M. (1999). Transmission dynamics of epidemic methicillinresistant Staphylococcus aureus and vancomycin-resistant enterococci in England and Wales. Journal of Infectious Diseases, Vol. 4, No. 4, (April 1999), pp. 883-91, ISSN 0022-1899

Austin, D.J.; Bonten, M.J.; Weinstein, R.A.; Slaughter, S. \& Anderson, R.M. (1999a). Vancomycin-resistant enterococci in intensive-care hospital settings: transmission dynamics, persistence, and the impact of infection control programs. Proceedings of the National Academy of Sciences, U S A, Vol. 96, No. 12 (June 1999), pp. 6908-13 ISSN 0027-8424 
Austin, D.J.; Kristinsson, K.G. \& Anderson, R.M. (1999b). The relationship between the volume of antimicrobial consumption in human communities and the frequency of resistance. Proceedings of the National Academy of Sciences, U S A, Vol. 96, No. 3, (February 1999), pp. 1152-6, ISSN 0027-8424

Aziz, R.K. \& Kotb, M. (2008). Rise and persistence of global M1T1 clone of Streptococcus pyogenes. Emerging Infectious Diseases, Vol. 14, No. 10, (October 2008), pp. 1511-7, ISSN 1080-6059

Bailey, N.T.J. (1975). The Mathematical Theory of Infectious Diseases and its Application, Griffin, ISBN 978-0195205640, London

Beggs, C.B.; Shepherd, S.J. \& Kerr, K.G. (2008). Increasing the frequency of hand washing by healthcare workers does not lead to commensurate reductions in staphylococcal infection in a hospital ward. BMC Infectious Diseases, Vol. 8, No. 114, (September 2008), pp. 1-11, ISSN 1471-2334

Beggs, C.B.; Shepherd, S.J. \& Kerr, K.G. (2009). How does healthcare worker hand hygiene behaviour impact upon the transmission of MRSA between patients? An analysis using a Monte Carlo model. BMC Infectious Diseases, Vol. 9, No. 64, (May 2009), pp. 1-9, ISSN 1471-2334

Beggs, C.B.; Shepherd, S.J. \& Kerr, K.G. (2010).Potential for airborne transmission of infection in the waiting areas of healthcare premises: stochastic analysis using a Monte Carlo model BMC Infectious Diseases, Vol. 10, (August 2010), pp. 1-8, ISSN 1471-2334

Besier, S.; Ludwig, A.; Brade, V. \& Wichelhaus, T.A. (2005). Compensatory adaptation to the loss of biological fitness associated with acquisition of fusidic acid resistance in Staphylococcus aureus. Antimicrobial Agents and Chemotherapy, Vol. 49, No. 4, (April 2005), pp. 1426-31, ISSN 0066-4804

Bode, L.G.; Wertheim, H.F.; Kluytmans, J.A.; Bogaers-Hofman, D.; Vandenbroucke-Grauls, C.M.; Roosendaal, R.; Troelstra, A.; Box, A.T; Voss, A.; van Belkum, A.; Verbrugh. H.A. \& Vos, M.C. (2011). Journal of Hospital Infectinon, Vol. 2011 Jul 13. [Epub ahead of print] Sustained low prevalence of meticillin-resistant Staphylococcus aureus upon admission to hospital in The Netherlands.

Bonten, M.J.; Hayden, M.K.; Nathan, C.; van Voorhis, J.; Matushek, M.; Slaughter, S.; Rice, T. \& Weinstein, R.A. Epidemiology of colonisation of patients and environment with vancomycin-resistant enterococci. Lancet, Vol. 348, No. 9042, (December 1996), pp. 1615-9, ISSN 0140-6736

Bonten, M.J.; Austin, D.J. \& Lipsitch, M. (2001). Understanding the spread of antibiotic resistant pathogens in hospitals: mathematical models as tools for control. Clinical Infectious Diseases, Vol. 33, No. 10, (November 2001), pp. 1739-46 ISSN 1058-4838

Bootsma, M.C.; Diekmann, O. \& Bonten, M.J. (2006). Controlling methicillin-resistant Staphylococcus aureus: quantifying the effects of interventions and rapid diagnostic testing. Proceedings of the National Academy of Sciences, USA, Vol.103, No. 14, (April 2006), pp. 5620-5, ISSN 0027-8424

Bootsma, M.C.; Bonten, M.J.; Nijssen, S.; Fluit, A.C. \& Diekmann, O. (2007). An algorithm to estimate the importance of bacterial acquisition routes in hospital settings. 
American Journal of Epidemiology, Vol. 166, No. 7, (October 2007), pp. 841-51, ISSN 0002-9262

Bryan, C.S. \& Reynolds, K.L. (1984). Hospital-acquired bacteremic urinary tract infection: epidemiology and outcome. Journal of Urology, Vol. 132, No. 3, (September 1984), pp. 494-8, ISSN 0022-5347

Carlin, B.P. \& Louis, T.A. (2000). Bayes and Empirical Bayes Methods for Data Analysis (second edition), Chapman \& Hall/CRC, ISBN 1-58488-170-4, Florida, USA

Cepeda, J.A.; Whitehouse, T; Cooper, B.; Hails, J.; Jones, K.; Kwaku, F.; Taylor, L.; Hayman, S.; Cookson, B.; Shaw, S.; Kibbler, C.; Singer, M.; Bellingan, G. \& Wilson, A.P. (2005). Isolation of patients in single rooms or cohorts to reduce spread of MRSA in intensive-care units: prospective two-centre study. Lancet, Vol. 365, No. 9456, (January 2005), pp. 295-304, ISSN 1474-547X

Cipolla, C.M. (1973). Cristofano and the Plague. The Study of the History of Public Health in the Age of Galileo, Collins, ISBN 0002111918, London

Coello, R.; Glynn, J.R.; Gaspar, C.; Picazo, J.J. \& Fereres, J. (1997). Risk factors for developing clinical infection with methicillin-resistant Staphylococcus aureus (MRSA) amongst hospital patients initially only colonized with MRSA. Journal of Hospital Infection, Vol. 37, No. 1, (September 1997), pp. 39-46, ISSN 0195-6701

Coen, P.G. (2007). How mathematical models have helped to improve understanding the epidemiology of infection. Early Human Development, Vol. 83, No. 3, (February 2007), pp. 141-8, ISSN 0378-3782

Cook, P.P.; Catrou, P.G.; Christie, J.D.; Young, P.D. \& Polk, R.E. (2004). Reduction in broadspectrum antimicrobial use associated with no improvement in hospital antibiogram. Journal of Antimicrobial Chemotherapy, Vol. 53, No. 5, (May 2004), pp. 853-9, ISSN 0305-7453

Cooper, B.S.; Medley, G.F. \& Scott, G.M. (1999). Preliminary analysis of the transmission dynamics of nosocomial infections: stochastic and management effects. Journal of Hospital Infection, Vol. 43, No. 2, (October 1999), pp. 131-47, ISSN 0195-6701

Cooper, B. \& Lipsitch, M. (2004). The analysis of hospital infection data using hidden Markov models. Biostatistics, Vol. 5, No. 2, (April 2004), pp. 223-37, ISSN 1465-4644

Cooper, B.S.; Stone, S.P.; Kibbler, C.C.; Cookson, B.D.; Roberts, J.A.; Medley, G.F. et al. (2003). Systematic review of isolation policies in the hospital management of methicillin-resistant Staphylococcus aureus: a review of the literature with epidemiological and economic modelling. Health Technology Assessment, Vol. 7, No. 39, (December 2003), ISSN 1366-5278

Cooper, B.S.; Medley, G.F.; Stone, S.P.; Kibbler, C.C.; Cookson, B.D.; Roberts, J.A.; Duckworth, G.; Lai, R. \& Ebrahim, S. (2004a). Methicillin-resistant Staphylococcus aureus in hospitals and the community: stealth dynamics and control catastrophes. Proceedings of the National Academy of Sciences, USA, Vol. 101, No. 27, (July 2004), pp. 10223-8, ISSN 0027-8424

Cooper, B.S.; Stone, S.P.; Kibbler, C.C.; Cookson, B.D.; Roberts, J.A.; Medley, G.F.; Duckworth, G.; Lai, R. \& Ebrahim, S. (2004b) Isolation measures in the hospital management of methicillin resistant Staphylococcus aureus (MRSA): systematic review of the literature. British Medical Journal, Vol. 329, No. 7465, (September 2004), pp. 1-8, ISSN 1468-5833 
Cooper, B.S.; Medley, G.F.; Bradley, S.J. \& Scott, G.M. (2008). An augmented data method for the analysis of nosocomial infection data. American Journal of Epidemiology, Vol. 168, No. 5, (September 2008), pp. 548-57, ISSN 1476-6256

Cooper, B. \& Lipsitch, M. (2004). The analysis of hospital infection data using hidden Markov models. Biostatistics, Vol. 5, No. 2, (April 2004), pp. 223-37, ISSN 14654644

Cullik, A.; Pfeifer, Y.; Prager, R.; von Baum, H. \& Witte, W. A novel IS26 structure surrounds blaCTX-M genes in different plasmids from German clinical Escherichia coli isolates. Journal of Medical Microbiology, Vol. 59, No. 5, (May 2010), pp. 580-7, ISSN 1473-5644

David, M.Z. \& Daum, R.S. (2010). Community-associated methicillin-resistant Staphylococcus aureus: epidemiology and clinical consequences of an emerging epidemic. Clinical Microbiology Reviews, Vol. 23, No. 3, (July 2010), pp. 616-87, ISSN 1098-6618

Dall'Antonia, M.; Coen, P.G.; Wilks, M.; Whiley, A. \& Millar, M. (2005). Competition between methicillin-sensitive and -resistant Staphylococcus aureus in the anterior nares. Journal of Hospital Infection, Vol. 61, No. 1, (September 2005), pp. 62-7, ISSN 0195-6701

de Bruin, E.; Duizer, E.; Vennema, H. \& Koopmans, M.P. (2006). Diagnosis of Norovirus outbreaks by commercial ELISA or RT-PCR. Journal of Virological Methods, Vol. 137, No. 2, (November 2006), pp. 259-64, ISSN 0166-0934

Edgeworth, J.D. (2010). Has decolonization played a central role in the decline in UK methicillin-resistant Staphylococcus aureus transmission? A focus on evidence from intensive care. Journal of Antimicrobial Chemotherapy, Vol. 66, Suppl. 2, (April 2010), pp. ii41-ii47, ISSN 1460-2091

Edwards, A.W.F. (1972). Likelihood. Cambridge University Press, Cambridge, ISBN 0-52131871-8, Cambridge

Enne, V.I.; Livermore, D.M.; Stephens, P. \& Hall, L.M. (2001). Persistence of sulphonamide resistance in Escherichia coli in the UK despite national prescribing restriction. Lancet, Vol. 357, No. 9265, (April 2001), pp. 1325-8, ISSN 0140-6736

Enne, V.I.; Bennett, P.M.; Livermore, D.M. \& Hall, L.M. (2004). Enhancement of host fitness by the sul2-coding plasmid p9123 in the absence of selective pressure. Journal of Antimicrobial Chemotherapy, Vol. 53, No. 6, (April 2004), pp. 958-63, ISSN 0305-7453

Feil, E.J.; Cooper, J.E.; Grundmann, H.; Robinson, D.A.; Enright, M.C.; Berendt, T.; Peacock, S.J.; Smith, J.M.; Murphy, M.; Spratt, B.G.; Moore, C.E \& Day, N.P. (2003). How clonal is Staphylococcus aureus? Journal of Bacteriology, Vol. 185, No. 11, (June 2003), pp. 3307-16, ISSN 0021-9193

Fraser, C.; Hanage, W.P. \& Spratt, B.G. (2005). Neutral microepidemic evolution of bacterial pathogens. Proceedings of the National Academy of Sciences, USA, Vol. 102, No. 6, (February 2005), pp. 1968-73, ISSN 0027-8424

Fukutome, A.; Watashi, K.; Kawakami, N. \& Ishikawa, H. (2007). Mathematical modeling of severe acute respiratory syndrome nosocomial transmission in Japan: the dynamics of incident cases and prevalent cases. Microbiology and Immunology, Vol. 51, No. 9, (June 2007), pp. 823-32, ISSN 0385-5600 
Forrester, M.L.; Pettitt, A.N. \& Gibson, G.J. (2007). Bayesian inference of hospital-acquired infectious diseases and control measures given imperfect surveillance data. Biostatistics, Vol. 8, No. 2, (April 2007), pp. 383-401, ISSN 1465-4644

Griffiths, D.; Fawley, W.; Kachrimanidou, M.; Bowden, R.; Crook, D.W.; Fung, R.; Golubchik. T.; Harding, R.M.; Jeffery, K.J.; Jolley, K.A.; Kirton, R.; Peto, T.E.; Rees, G.; Stoesser, N.; Vaughan, A.; Walker, A.S.; Young, B.C.; Wilcox, M. \& Dingle, K.E. Multilocus sequence typing of Clostridium difficile. Journal of Clinical Microbiology, Vol. 48, No. 3, (March 2010), pp. 770-8, ISSN 0095-1137

Grigg, O.A.; Farewell, V.T. \& Spiegelhalter, D.J. (2003). Use of risk-adjusted CUSUM and RSPRT charts for monitoring in medical contexts. Statistical Methods in Medical Research, Vol. 12, No. 2, (March 2003), pp. 147-70, ISSN 0962-2802

Grundmann, H.; Hori, S.; Winter, B.; Tami, A. \& Austin, D.J. (2002). Risk factors for the transmission of methicillin-resistant Staphylococcus aureus in an adult intensive care unit: fitting a model to the data. Journal of Infectious Diseases, Vol. 185, No. 4, (February 2001), pp. 481-8, ISSN 0022-1899

Grundmann, H.; Livermore, D.M.; Giske, C.G.; Canton, R.; Rossolini, G.M.; Campos, J.; Vatopoulos, A.; Gniadkowski, M.; Toth, A.; Pfeifer, Y.; Jarlier, V.; Carmeli, Y. \& CNSE Working Group (2010). Carbapenem-non-susceptible Enterobacteriaceae in Europe: conclusions from a meeting of national experts. Eurosurveillance, Vol. 15, No. 46, (November 2010), pp. 1-13, ISSN 1560-7917

Haber, M.; Levin, B.R. \& Kramarz, P. (2010). Antibiotic control of antibiotic resistance in hospitals: a simulation study. BMC Infectious Diseases, Vol. 10, (August 2010), pp. 110, ISSN 1471-2334

Hamilton, D.; Foster, A.; Ballantyne, L.; Kingsmore, P.; Bedwell, D.; Hall, T.J.; Hickok, S.S.; Jeanes, A.; Coen, P.G. \& Gant, V.A. (2010). Performance of ultramicrofibre cleaning technology with or without addition of a novel copper-based biocide. Journal of Hospital Infection, Vol. 74, No. 1, (January 2010), pp. 62-71, ISSN 1532-2939

Harris, J.P.; Lopman, B.A. \& O'Brien, S.J. (2010). Infection control measures for norovirus: a systematic review of outbreaks in semi-enclosed settings. Journal of Hospital Infection, Vol. 74, No. 1, (January 2010), pp. 1-9, ISSN 1532-2939

Health Protection Agency (2011a). Protocol for the Surveillance of Surgical Site Infection, Version 5, April 2011, Retrieved from <http://www.hpa.org.uk>

Health Protection Agency (2011b). Clostridium difficile Ribotyping Network (CDRN) for England and Northern Ireland, 2009/10 Report, Retrieved from <http://www.hpa.org.uk>

Health Protection Agency (2011c). PVL-Staphylococcal infections an update. Health Protection Report, Vol. 5, No. 7, Retrieved from <http://www.hpa.org.uk>

Höhle, M.; Jørgensen, E. \& O'Neill, P.D. (2005). Inference in disease transmission experiments by using stochastic epidemic models. Journal of the Royal Statistical Society: Series C (Applied Statistics), Vol. 54, No. 2, (January 2005), pp. 349-366, ISSN 1467-9876

Hospital Infection Society \& Infection Control Nurses Association (2007). The third prevalence survey of healthcare associated infection in acute hospitals, 2006. Preliminary results from England, Retrieved from: <http://www.his.org.uk> 
Hubben, G.; Bootsma, M.; Luteijn, M.; Glynn, D., Bishai, D.; Bonten, M. \& Postma, M. (2011). Modelling the costs and effects of selective and universal hospital admission screening for methicillin-resistant Staphylococcus aureus. PLoS One, Vol. 6, No. 3, (March 2011), pp. 1-11, ISSN 1932-6203

Huskins, W.C. \& Goldmann, D.A. (2005). Controlling meticillin-resistant Staphylococcus aureus, aka "Superbug". Lancet, Vol. 365, No. 9456, (January 2005), pp. 273-5, ISSN 1474-547X

Jeanes, A.; Macrae, B. \& Ashby, J. (2011). Isolation prioritization tool: revision, adaptation and application. British Journal of Nursing, Vol. 20, No. 9, pp. 540-544, ISSN 09660461

Jernigan, J.A.; Titus, M.G.; Gröschel, D.H.; Getchell-White, S. \& Farr, B.M. (1996). Effectiveness of contact isolation during a hospital outbreak of methicillin-resistant Staphylococcus aureus. American Journal of Epidemiology, Vol. 143, No. 5, (March 1996), pp. 496-504, ISSN 0002-9262

Johnson, S.; Clabots, C.R.; Linn, F.V.; Olson, M.M.; Peterson, L.R. \& Gerding, D.N. (1990). Nosocomial Clostridium difficile colonisation and disease. Lancet, Vol. 336, No. 8707, (July 1990), pp. 97-100, ISSN 0140-6736

Kouyos, R.D.; Abel Zur Wiesch, P. \& Bonhoeffer, S. (2011). Informed switching strongly decreases the prevalence of antibiotic resistance in hospital wards. PLoS Computational Biology, Vol. 7, No. 3, (March 2011), pp. 1-10, ISSN 1553-7358

Kypraios, T.; O'Neill, P.D.; Huang, S.S.; Rifas-Shiman, S.L. \& Cooper, B.S. (2010). Assessing the role of undetected colonization and isolation precautions in reducing methicillin-resistant Staphylococcus aureus transmission in intensive care units. BMC Infectious Diseases, Vol. 10, No. 29, (February 2010), pp. 1-10, ISSN 1471-2334

La Force, F.M. (1987). The Control of Infections in Hospitals: 1750 to 1950, In: Prevention and Control of Nosocomial Infections, R.P. Wenzel (Ed.), pp.1-12, Williams \& Wilkins, Baltimore, USA, ISBN 0-683-08923-4

Levin, B.R. (2002). Models for the spread of resistant pathogens. Netherlands Journal of Medicine, Vol. 60, No. 7, (August 2002), pp. 58-64, ISSN 0300-2977

Lipsitch, M.; Bergstrom, C.T. \& Levin, B.R. (2000). The epidemiology of antibiotic resistance in hospitals: paradoxes and prescriptions. Proceedings of the National Academy of Sciences, USA, Vol. 97, No. 4, (February 2000), pp. 1938-43, ISSN 0027-8424

Livermore, D.M.; Winstanley, T.G. \& Shannon, K.P. (2001). Interpretative reading: recognizing the unusual and inferring resistance mechanisms from resistance phenotypes. Journal of Antimicrobial Chemotherapy, Vol. 48, Suppl. 1, (July 2001), pp. 87-102, ISSN 0305-7453

Lopman, B.A.; Reacher, M.H.; Vipond, I.B.; Sarangi, J. \& Brown, D.W. (2004). Clinical manifestation of norovirus gastroenteritis in health care settings. Clinical Infectious Diseases, Vol. 39, No. 3, (July 2004), pp. 318-324, ISSN 1537-6591

Lu, P.L.; Chin, L.C.; Peng, C.F.; Chiang, Y.H.; Chen, T.P.; Ma, L. \& Siu, L.K. (2005). Risk factors and molecular analysis of community methicillin-resistant Staphylococcus aureus carriage. Journal of Clinical Microbiology, Vol. 43, No. 1, (January 2005), pp. 132-9, ISSN 0095-1137 
McBryde, E.S.; Pettitt, A.N. \& McElwain, D.L. (2007). A stochastic mathematical model of methicillin resistant Staphylococcus aureus transmission in an intensive care unit: predicting the impact of interventions. Journal of Theoretical Biology, Vol. 245, No. 3, (April 2007), pp. 470-81, ISSN 0022-5193

Metropolis, N.; Rosenbluth, A.W.; Rosenbluth, M.N.; Teller, A.H. \& Teller, E. (1953). Equations of State Calculations by Fast Computing Machines. Journal of Chemical Physics, Vol. 21, No. 6, pp. 1087-1092, ISSN 00219606

Milkman, R. \& Bridges, M.M. (1990). Molecular evolution of the Escherichia coli chromosome. III. Clonal frames. Genetics, Vol. 126, No. 3, (November 1990), pp. 505-17, ISSN 0016-6731

Oie, S.; Yanagi, C.; Matsui, H.; Nishida, T.; Tomita, M. \& Kamiya, A. (2005). Contamination of environmental surfaces by Staphylococcus aureus in a dermatological ward and its preventive measures Biological \& pharmaceutical bulletin, Vol. 28, No. 1, (January 2005), pp. 120-3, ISSN 0918-6158

Ong, B.S.; Chen, M.; Lee, V. \& Tay, J.C. (2008). An individual-based model of influenza in nosocomial environments, In: Proceedings of the 8th international conference on Computational Science, Part I, pp. 590-599, Springer-Verlag, ISBN 978-3-540-69383-3, Berlin

Pelupessy, I.; Bonten, M.J. \& Diekmann, O. (2002). How to assess the relative importance of different colonization routes of pathogens within hospital settings. Proceedings of the National Academy of Sciences, USA, Vol. 99, No. 8, (April 2002), pp. 5601-5, ISSN 0027-8424

Pelupessy I, Bonten MJ, Diekmann O. Phillips, G.; Tam, C.C.; Rodrigues, L.C. \& Lopman, B. (2010). Prevalence and characteristics of asymptomatic norovirus infection in the community in England. Epidemiology and Infection, Vol. 138, No. 10, (October 2010), pp. 1454-8, ISSN 1469-4409

Pittet, D.; Mourouga, P. \& Perneger, T.V. (1999). Compliance with handwashing in a teaching hospital. Infection Control Program. Annals of Internal Medicine, Vol. 130, No. 2, (January 1999), pp. 126-30, ISSN 0003-4819

Plowman, R.; Graves, N.; Griffin, M.; Roberts, J.A.; Swan, A.; Cookson, B. et al. (1999). The socio-economic burden of hospital acquired infection, In: Department of Health (date of access: 15th September 2011), Available from: http:/ / www.doh.gov.uk.

Press, W.H.; Teukolsky, S.A.; Vetterling, W.T. \& Flannery, B.P. (1994). Numerical Recipes in Fortran, the Art of Scientific Computing (second edition), Cambridge University Press, ISBN 0-521-43064-X

Raboud, J.; Saskin, R.; Simor, A.; Loeb, M.; Green, K.; Low, D.E. \& McGeer, A. (2005). Modeling transmission of methicillin-resistant Staphylococcus aureus among patients admitted to a hospital. Infection Control Hospital Epidemiology, Vol. 26, No. 7, (July 2005), pp. 607-15, ISSN 0899-823X

Renshaw, E. (1991). Modelling Biological Populations in Space and Time, Cambridge University Press, ISBN 0-521-44855-7, Cambridge

Robotham, J.V., Jenkins, D.R. \& Medley, G.F. (2007). Screening strategies in surveillance and control of methicillin-resistant Staphylococcus aureus (MRSA). Epidemiology and Infection, Vol. 135, No. 2, pp. 328-42, ISSN 0950-2688

Ross, S.M. (2006). Simulation, (4th edition), Academic Press, ISBN 0-12-598063-9 
Scott, M.E \& Smith, G. (1994). Parasitic and Infectious Diseases, Epidemiology and Ecology, Academic Press, ISBN 0-12-633325-4

Sébillé, V.; Chevret, S. \& Valleron, A.J. (1997). Modeling the spread of resistant nosocomial pathogens in an intensive-care unit. Infection Control and Hospital Epidemiology, Vol. 18, No. 2, (February 1997), pp. 84-92, ISSN 0899-823X

Smith, J.M.; Smith, N.H.; O'Rourke, M. \& Spratt, B.G. (1993). How clonal are bacteria? Proceedings of the National Academy of Sciences, USA, Vol. 90, No. 10, (May 1993), pp. 4384-8, ISSN 0027-8424

Smith, D.L.; Dushoff, J.; Perencevich, E.N.; Harris, A.D. \& Levin, S.A. (2004). Persistent colonization and the spread of antibiotic resistance in nosocomial pathogens: resistance is a regional problem. Proceedings of the National Academy of Sciences, USA, Vol. 101, No. 10, (March 2004), pp. 3709-14, ISSN 0027-8424

Sneader, W. (2005). Drug Discovery, a History, Wiley, ISBN 0-471-89979-8

Stewart, G.P. \& Holt, R.J. (1963). Evolution of natural resistance to the new penicillins. British Medical Journal, Vol. 1, No. 5326, pp. 308-11, ISSN 0007-1447

Sundqvist, M.; Geli, P.; Andersson, D.I.; Sjölund-Karlsson, M.; Runehagen, A.; Cars, H.; Abelson-Storby, K.; Cars, O. \& Kahlmeter, G. Journal of Antimicrobial Chemotherapy, Vol. 65, No. 2, (February 2010), pp. 350-60, ISSN 1460-2091

van Schaik, W. \& Willems, R.J. (2010). Genome-based insights into the evolution of enterococci. Clinical Microbiology of Infection, Vol. 16, No. =6, (June 2010), pp. 527-32, ISSN 1469-0691

Vinjé, J.; Vennema, H.; Maunula, L.; von Bonsdorff, C.H.; Hoehne, M.; Schreier, E.; Richards, A.; Green, J.; Brown, D.; Beard, S.S.; Monroe, S.S.; de Bruin, E.; Svensson, L. \& Koopmans, M.P. (2003). International collaborative study to compare reverse transcriptase PCR assays for detection and genotyping of noroviruses. Journal of Clinical Microbiology, Vol. 41, No. 4, (April 2003), pp. 142333, ISSN 0095-1137

Warny, M.; Pepin, J.; Fang, A.; Killgore, G.; Thompson, A.; Brazier, J.; Frost, E. \& McDonald, L.C. (2005). Toxin production by an emerging strain of Clostridium difficile associated with outbreaks of severe disease in North America and Europe. Lancet, Vol. 366, No. 9491, (September 2005), pp. 1079-84, ISSN 0140-6736

Wertheim, H.F.; Vos, M.C.; Boelens, H.A.; Voss, A.; Vandenbroucke-Grauls, C.M.; Meester, M.H.; Kluytmans, J.A.; van Keulen, P.H. \& Verbrugh, H.A. (2004). Low prevalence of methicillin-resistant Staphylococcus aureus (MRSA) at hospital admission in the Netherlands: the value of search and destroy and restrictive antibiotic use. Journal of Hospital Infection, Vol. 56, No. 4, (April 2004), pp. 321-5, ISSN 0195-6701

Wijngaarden, P.J.; van den Bosch, F.; Jeger, M.J. \& Hoekstra, R.F. (2005). Adaptation to the cost of resistance: a model of compensation, recombination, and selection in a haploid organism Proceedings of the Royal Society, London (Biological Sciences), Vol. 272, No. 1558, (January 2005), pp. 85-9, ISSN 0962-8452

Wyatt, R.G.; Dolin, R.; Blacklow, N.R.; DuPont, H.L.; Buscho, R.F.; Thornhill, T.S.; Kapikian, A.Z. \& Chanock, R.M. (1974). Comparison of three agents of acute infectious nonbacterial gastroenteritis by cross-challenge in volunteers. Journal of Infectious Diseases, Vol. 129, No. 6, (June 1974), pp. 709-14, ISSN 0022-1899 
Zagheni, E.; Billari, F.C.; Manfredi, P.; Melegaro, A.; Mossong, J. \& Edmunds, W.J. (2008). Using time-use data to parameterize models for the spread of close-contact infectious diseases. American Journal of Epidemiology, Vol. 168, No. 9, (November 2008), pp. 1082-90, ISSN 1476-6256

Zhao, F.; Bai, J.; Wu, J.; Liu, J.; Zhou, M.; Xia, S.; Wang, S.; Yao, X.; Yi, H.; Lin, M.; Gao, S.; Zhou, T.; Xu, Z.; Niu, Y. \& Bao, Q. (2010). Sequencing and genetic variation of multidrug resistance plasmids in Klebsiella pneumoniae. PLoS One, Vol. 5, No. 4, (April 2010), pp. 1-9, ISSN 1932-6203 


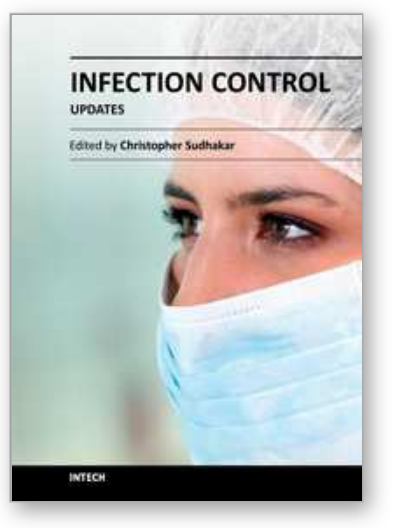

\author{
Infection Control - Updates \\ Edited by Dr. Christopher Sudhakar
}

ISBN 978-953-51-0055-3

Hard cover, 198 pages

Publisher InTech

Published online 22, February, 2012

Published in print edition February, 2012

Health care associated infection is coupled with significant morbidity and mortality. Prevention and control of infection is indispensable part of health care delivery system. Knowledge of Preventing HAI can help health care providers to make informed and therapeutic decisions thereby prevent or reduce these infections. Infection control is continuously evolving science that is constantly being updated and enhanced. The book will be very useful for all health care professionals to combat with health care associated infections.

\title{
How to reference
}

In order to correctly reference this scholarly work, feel free to copy and paste the following:

Pietro Coen (2012). Models of Hospital Acquired Infection, Infection Control - Updates, Dr. Christopher Sudhakar (Ed.), ISBN: 978-953-51-0055-3, InTech, Available from:

http://www.intechopen.com/books/infection-control-updates/how-to-model-infections-acquired-in-hospital

\section{INTECH}

open science | open minds

\author{
InTech Europe \\ University Campus STeP Ri \\ Slavka Krautzeka 83/A \\ 51000 Rijeka, Croatia \\ Phone: +385 (51) 770447 \\ Fax: +385 (51) 686166 \\ www.intechopen.com
}

\author{
InTech China \\ Unit 405, Office Block, Hotel Equatorial Shanghai \\ No.65, Yan An Road (West), Shanghai, 200040, China \\ 中国上海市延安西路65号上海国际贵都大饭店办公楼 405 单元 \\ Phone: +86-21-62489820 \\ Fax: $+86-21-62489821$
}


(C) 2012 The Author(s). Licensee IntechOpen. This is an open access article distributed under the terms of the Creative Commons Attribution 3.0 License, which permits unrestricted use, distribution, and reproduction in any medium, provided the original work is properly cited. 